\title{
Effect of Rotation Speed on Microstructure and Mechanical Properties of Friction-Stir-Welded 2205 Duplex Stainless Steel
}

\author{
Wenyang Wang $\mathbb{D}^{1,2}$ Ye Hu, ${ }^{1,2}$ Tong $W u^{1,2}$ Dan Zhao, ${ }^{1,2}$ and Hongwei Zhao $\mathbb{D}^{1,2}$ \\ ${ }^{1}$ School of Mechanical and Aerospace Engineering, Jilin University, Changchun 130025, China \\ ${ }^{2}$ Key Laboratory of CNC Equipment Reliability, Ministry of Education, Changchun 130025, China \\ Correspondence should be addressed to Hongwei Zhao; hwzhao@jlu.edu.cn
}

Received 20 August 2019; Revised 9 January 2020; Accepted 21 February 2020; Published 5 May 2020

Academic Editor: Guru P. Dinda

Copyright (C) 2020 Wenyang Wang et al. This is an open access article distributed under the Creative Commons Attribution License, which permits unrestricted use, distribution, and reproduction in any medium, provided the original work is properly cited.

In the present study, 1.86-mm-thick steel plates (UNS S32205) were friction-stir-welded at various rotation speeds of 300 to $600 \mathrm{rpm}$ and a constant welding speed of $100 \mathrm{~mm} \cdot \mathrm{min}^{-1}$. The effect of rotation speed on the microstructure and mechanical properties of the welds was researched. The welding temperature was recorded during friction stir welding (FSW), and the microstructure and mechanical properties of the welds were assessed. The incomplete penetration defect was formed at $300 \mathrm{rpm}$ due to the insufficient heat input, and macroscopic groove-like defect was formed at $600 \mathrm{rpm}$ because of the serious sticking of tool. Defect-free welds were obtained at 350 to $500 \mathrm{rpm}$. The lower rotation speed corresponds to lower heat input during FSW, which resulted in finer recrystallized grains within the stirred zone and thermomechanically affected zone. The joint width was increased with the increasing rotation speed. Therefore, both the strength and hardness of the weld joints increased with the decreasing of rotation speed.

\section{Introduction}

Duplex stainless steels (DSS) have been widely used in the marine and petrochemical industries due to the excellent corrosion resistance and mechanical properties, and its excellent corrosion resistance and mechanical properties rely on the perfect ratio of ferrite $(\alpha)$ to austenite $(\gamma)$ and fine $\alpha$ and $\gamma$ grains [1-4]. According to the alloy composition, DSS can be divided into three types: lean DSS, standard DSS, and super DSS $[2,3]$. The standard DSS exhibits higher pitting resistance equivalent number (PREN $=1 \quad \mathrm{wt} \%$ $\mathrm{Cr}+3.3 \mathrm{wt} \% \mathrm{Mo}+16 \mathrm{wt} \% \mathrm{~N})$ than lean DSS and better weldability than the super DSS [3]. Thus, as a standard DSS, 2205 DSS has been one of the most common types of DSS in the industry applications [3]. However, the fusion welding process might destroy the perfect ratio of $\alpha / \gamma$ in DSS and forms detrimental intermetallic phases and coarse $\alpha$ grains, which would damage the corrosion resistance and mechanical properties of the joints $[3,5-8]$. To further promote the industry application of 2205 DSS, it is urgent to promote the welding technology for DSS.
As a solid-state processing technology, friction stir welding (FSW) is a possible solution for these problems arisen in fusion welding of DSS. In recent years, a number of efforts focusing on FSW of DSS have been reported, such as lean DSS [9, 10], 2205 DSS [4, 11-13], SAF 2507 [14, 15], SAF 2707 [16, 17], etc. Due to the solid-state nature of FSW, the heat input during FSW is significantly lower than that of fusion welding. In the study on FSW of 2205 DSS, Santos et al. [11] showed that the peak temperature during FSW is lower than the phase transition temperature of $\gamma$ to $\alpha$. In addition, Emami et al. [4] and Saeid et al. [18] studied the microstructure of the joints using electron backscattering diffraction (EBSD) analysis; they found that the phase ratio of $\alpha$ to $\gamma$ in the stirred zone (SZ) is roughly the same as the base metal (BM). Previous studies on FSW of 2205 DSS $[4,13,18,19]$ indicate that FSW can significantly refine the $\alpha$ and $\gamma$ grains through dynamic recrystallization (DRX), and the hardness and strength of the joints are improved.

Both welding speed and rotation speed are important parameters for FSW. Previous researches on FSW [20, 21] indicate that both the rotation speed and welding speed have 
significant influence on welding temperature and deformation degree and then influence the microstructure evolution and mechanical properties of the joints. In a study on FSW of 2205 DSS, Saeid et al. [12] showed that the grains within stir zone decrease with the increasing welding speed because the heat input also decreases with the increasing welding speed. And Esmailzadeh et al. [9] also found a similar relationship between welding speed and the grain size within SZ in a study on FSW of lean DSS. In regard to rotation speed, there are many studies that focus on the effect of rotation speed on FSW of Al alloys. Mishra et al. [20] reported that the recrystallized grain in the FS-welded $\mathrm{Al}$ alloys generally increases with the increasing rotation speed because the increasing of the rotation speed would increase the peak temperature and cooling time. In the study on FSW of SAF 2707, Chen et al. [16] found that the grains within SZ decrease with the decreasing rotation speed due to the corresponding lower heat input. However, large amount of $s$ phases would form at the bottom of SZ when the rotation speed is lower than $300 \mathrm{rpm}$, and this phenomenon is explained by the temperature distribution and high $\mathrm{Cr}$ and Ni contents in SAF 2707, whereas Yabuuchi et al.'s study on FSW of an oxide-dispersion-strengthened steel [22] showed that the grain size within SZ has no systematic relationship with the rotation speed.

It is obvious that many efforts have been made on the welding parameters of FSW. But the effect of rotation speed on FSW of different materials is different; its effect on the microstructure and mechanical properties of FS-welded standard DSS is still not clear. Up to now, systematic study on the effect of rotation speed on the FSW of standard DSS has never been reported. In the present study, the effect of rotation speed on the FSW of 2205 DSS is thoroughly investigated. The phenomenon of serious sticking of tool was reported. The effect of rotation speed and the resulted heat input on the microstructure and mechanical properties of the joints are thoroughly discussed.

\section{Materials and Methods}

The base metal (BM) used in this research is commercial 2205 DSS (UNS 32205) with a thickness of $1.86 \mathrm{~mm}$. Its chemical compositions and mechanical properties are shown in Table 1. Before welding, the plate was machined to $150 \mathrm{~mm} \times 50 \mathrm{~mm}$ samples. The samples were welded by a vertical milling machine along the rolling direction. A tungsten-rhenium-based FSW tool with unthreaded pin was used in present study, and its geometry is shown in Figure 1(a). During the welding, the tool tilt angle was maintained at $2^{\circ}$; argon shielding gas was used to avoid the oxidation of the joints. Six welds were welded at various rotation speeds of $300,350,400,450,500$, and $600 \mathrm{rpm}$ and constant welding speed of $100 \mathrm{~mm} \cdot \mathrm{min}^{-1}$. And the pin insertion depth is also an important parameter of FSW $[20,23]$, which was kept at about $1.70 \mathrm{~mm}$ (Figure 1(a)).

In order to prevent the specimens welded together with the backing plate, thin layer $(1 \mathrm{~mm})$ of alumina ceramic, with high thermal conductivity, was placed between the specimens and the hot-mold steel based backing plate as shown in
Figure 1(b). The welding temperature was measured by a K-type thermocouple fixed in a $2.0 \mathrm{~mm}$ diameter hole in the backing plate with high-temperature cement; the hole was located under the centerline of the weld (Figure 1(b)). The temperature measured is used to compare the effect of rotation speeds on the thermal history, since it is difficult to measure the actual temperature within the stirred zone $[11,24]$.

The optical microscopy (OM) and scanning electron microscopy (SEM) were used to observe the microstructure of the welds. The energy-dispersive X-ray spectroscopy (EDS) was used to measure the chemical compositions of the microstructure. The metallographic samples of weld cross section were ground and polished in standard metallographic process and electroetched with two kinds of solutions. When using $\mathrm{KOH}$ solution $(56 \mathrm{~g} \mathrm{KOH}+100 \mathrm{ml}$ distilled water), only the ferrite phase can be etched; the phase ratio of $\gamma$ to $\alpha$ can be calculated accurately; when using oxalic acid solution ( $10 \mathrm{~g}$ oxalic acid $+90 \mathrm{ml}$ distilled water), both $\gamma$ and $\alpha$ grains can be etched, and their grain sizes can be obtained by metallographic analysis. The volume fractions of ferrite in different regions within the joints were calculated from the SEM photographs using Image-Pro Plus software, and the grain sizes of $\gamma$ and $\alpha$ grains were measured from the SEM photographs using Nano Measurer software.

The phase of weld cross section was analyzed by X-ray diffraction (XRD), which was carried out using a $\mathrm{D} / \mathrm{max}$ 2500 Rigaku diffractometer, performed with $\mathrm{Cu} \mathrm{Ka}$ radiation at $50 \mathrm{kV}$ and $200 \mathrm{~mA}$.

The mechanical properties were tested by Vickers hardness and tensile tests. The Vickers hardness of the weld cross section was measured along the midthickness line with a $4.9 \mathrm{~N}$ load for $10 \mathrm{~s}$. The transverse tensile tests were experimented at $20^{\circ} \mathrm{C}$ with $0.001 \mathrm{~s}^{-1}$ strain rate; the size of tensile samples is shown in Figure 2.

\section{Results and Discussion}

3.1. Weld Thermal History. The weld thermal history and peak temperature at different rotational speeds are shown in Figure 3. It can be seen that the peak temperature is positively correlated with rotation speed. However, the 1-mmthick alumina ceramic caused the temperature difference between SZ and thermocouple during welding; the measured temperature is lower than the actual temperature in SZ. In future studies, we will improve the temperature measuring method to record the actual temperature within the welds. Nevertheless, these results show some significant effect of rotational speed on welding temperature. It indicates that the higher rotation speed leads to the higher peak temperature and longer thermal period (Figure 3 ).

The previous researches $[12,20]$ suggested that the peak temperature $\left(T_{p}\right)$ during FSW is mainly related to the rotation speed $(\omega)$ and welding speed $(v)$, and the relationship among $T_{p}$, $\omega$, and $v$ can be expressed by following equation:

$$
\frac{T_{p}}{T_{m}}=K\left(\frac{\omega^{2}}{v \times 10^{4}}\right)^{\beta},
$$


TABLE 1: Chemical composition (wt\%) and mechanical properties of BM.

\begin{tabular}{|c|c|c|c|c|c|c|c|c|c|}
\hline $\mathrm{Cr}$ & $\mathrm{Ni}$ & Mo & $\mathrm{Mn}$ & C & $P$ & S & Tensile strength & Elongation & Hardness \\
\hline 22.42 & 5.17 & 3.07 & 1.22 & 0.021 & 0.029 & 0.005 & $(896 \pm 3.8) \mathrm{MPa}$ & $(28 \pm 0.5) \%$ & $(255 \pm 5) \mathrm{HV}$ \\
\hline
\end{tabular}

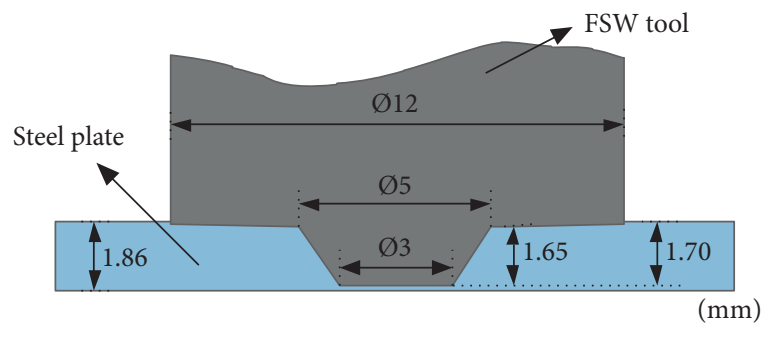

(a)

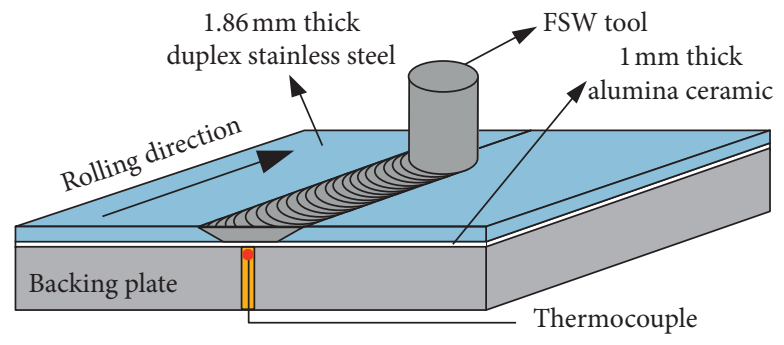

(b)

FIGURE 1: (a) Schematic illustration of the tool geometry and penetration depth. (b) Schematic illustration of experimental configuration for the FSW process.

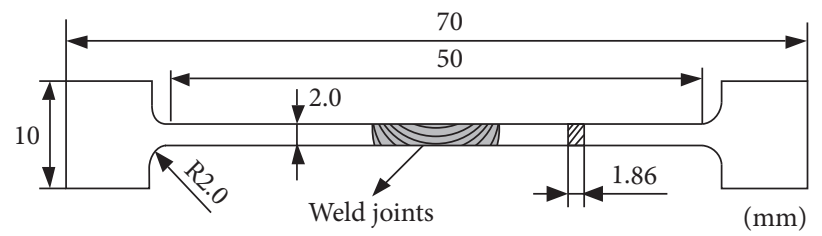

FIGURE 2: Schematic illustration of the transverse tensile sample.

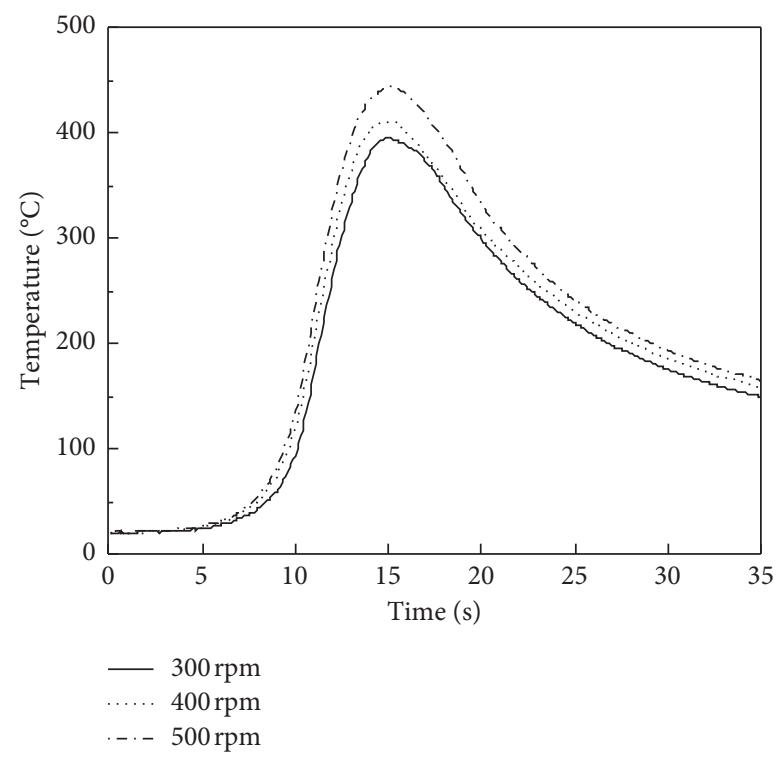

(a)

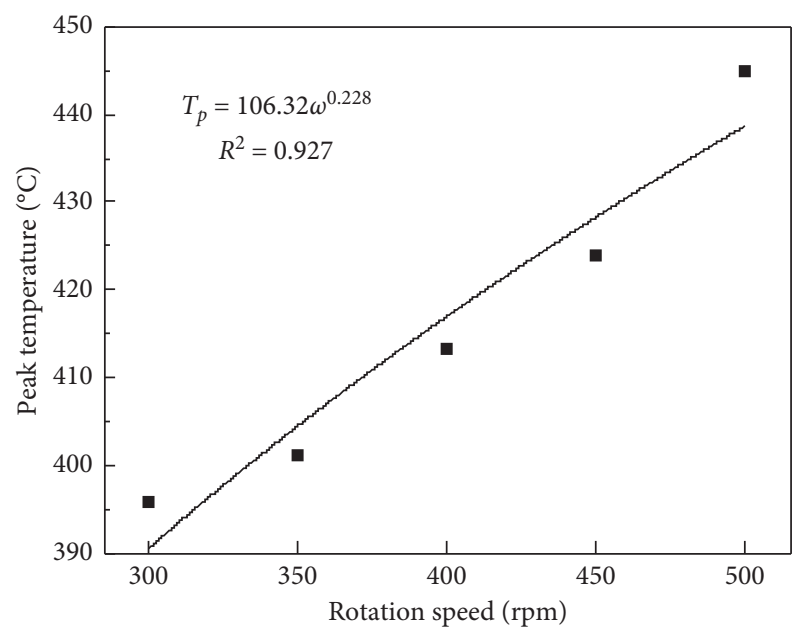

(b)

FIGURE 3: (a) Welding temperature measured at various rotation speeds. (b) The peak temperatures as a function of rotation speed.

where $T_{m}\left({ }^{\circ} \mathrm{C}\right)$ is the melting point of the alloy and $K$ and $\beta$ are constants. According to (1) and the experimental results in this research, the equation of $\omega(\mathrm{rpm})$ and $T_{p}\left({ }^{\circ} \mathrm{C}\right)$ was obtained as follows:

$$
T_{p}=106.32 \omega^{0.228}
$$

It is obvious that the higher $\omega$ matched with higher $T_{p}$. And $T_{p}$ is directly corresponding to $\mathrm{HI}$ produced by plastic 
deformation of workpiece and the friction between workpiece and tool $[11,16,20,25,26]$. The produced HI can be obtained by the following equation $[11,16]$ :

$$
H I=2 \pi \frac{M \omega}{1000 v}\left[\frac{k J}{\mathrm{~mm}}\right],
$$

where $M(\mathrm{~N} \mathrm{~m})$ is the spindle torque of the FSW machine. Chen et al.'s study on the HI of FSW [27] showed that HI is in proportion to $\omega$. In the present study, at constant tool pin insertion depth and $v$, higher HI was obtained at higher $\omega$, which resulted in the higher peak temperature and longer cooling time as shown in Figure 3. Previous studies $[9,12]$ showed that peak temperature has significant influence on the microstructure of FS-welded DSS, which will be discussed in detail in the following sections.

3.2. Serious Sticking of Tool. The macrographs of top surface of FSW joints in various rotation speeds are shown in Figure 4 ; it is clearly seen that sound joints were obtained at the rotation speed of $350,400,450$, and $500 \mathrm{rpm}$. At the rotation speed of $300 \mathrm{rpm}$, some small cracks were formed along the arc texture due to the insufficient material flow during welding. As discussed in Section 3.1, rotation speed is positively correlated with heat input during FSW. At the rotation speed of $300 \mathrm{rpm}$, both the heat input and the corresponding deformation degree were insufficient, which resulted in the insufficient material flow within the weld zone. However, at a higher rotation speed of $600 \mathrm{rpm}$, a groove-like defect is observed in the joint (Figure 4(a)). Previous studies $[12,28]$ revealed that groove-like defects are primarily formed when the heat input is insufficient during FSW. But the higher rotation speed is corresponding to higher heat input. Obviously, the heat input at $600 \mathrm{rpm}$ is adequate. As shown in Figure 5(a), the tool has serious sticking after welding at $600 \mathrm{rpm}$, which changed the structure of tool, resulted in the lack of material flow at the stirred zone, and formed the groove-like defect. Considering that the sticking of tool might influence the next welding, after each welding pass on 2205 DSS, the tool was cleaned by friction stir processing on a 3-mm-thick 304 austenite stainless steel plate. The sticking on tungsten-rhenium based tool was rarely reported in previous studies. At shown in Figure 5(b), the tool has a slight sticking after welding at $500 \mathrm{rpm}$. And at lower speed, this phenomenon was not obvious. These results indicate that the sticking of tool was closely related to the rotation speed; the high rotation speed would result in the serious sticking on tungsten-rheniumbased tool during FSW of 2205 DSS.

3.3. Macrographs and Microstructure of the Welds. The macrographs and microstructure of the weld cross sections welded at various rotation speeds are shown in Figure 6. It can be seen that defect-free welds are formed at rotation speeds of 350 to $500 \mathrm{rpm}$ (Figure 6(a)), whereas at lower rotation speed of $300 \mathrm{rpm}$, as shown in Figure 6(c), the lack of penetration defect was formed, and the microstructure at the bottom of the SZ maintained the cold-rolled
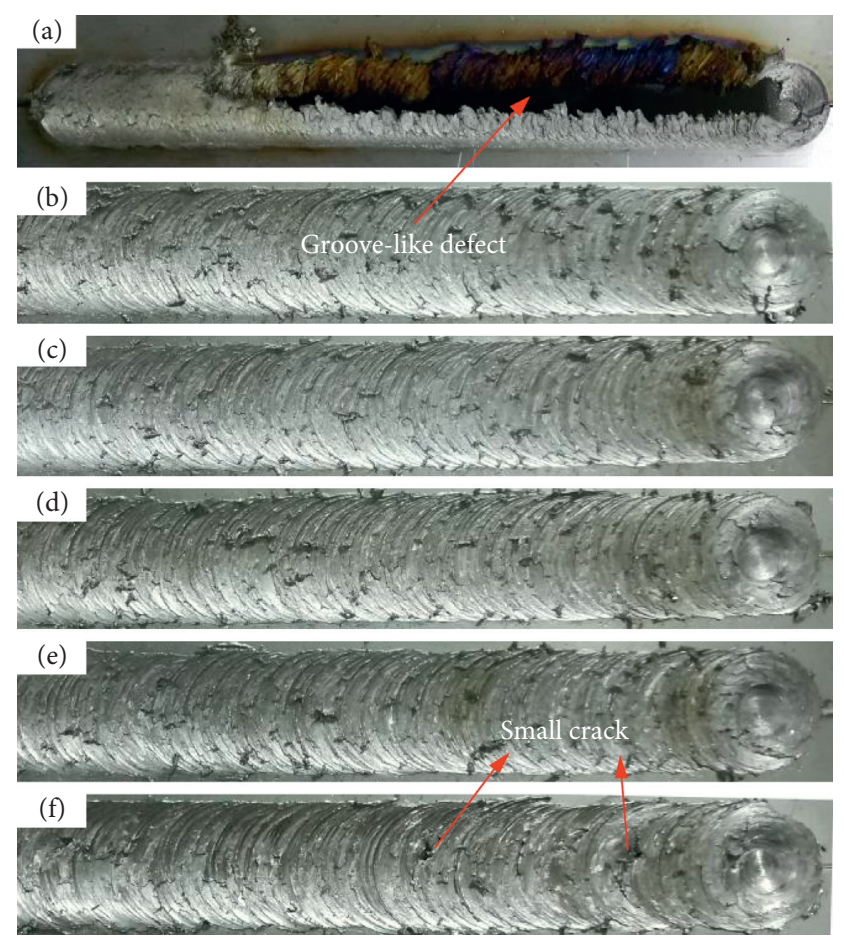

FIGURE 4: Macrographs of top surface of FSW joints weld at various rotation speeds: (a) $600 \mathrm{rpm}$, (b) $500 \mathrm{rpm}$, (c) $450 \mathrm{rpm}$, (d) $400 \mathrm{rpm}$, (e) $350 \mathrm{rpm}$, and (f) $300 \mathrm{rpm}$.

characteristic, which indicates that the material flow was insufficient and the recrystallization did not occur. As discussed above, the joint welded at $300 \mathrm{rpm}$ experienced the least HI and deformation, which resulted in the lack of penetration defect.

As shown in Figure 6(a), the microstructures of the friction stir welds of 2205 DSS can be divided into stirred zone (SZ) and thermomechanically affected zone (TMAZ). Different from $\mathrm{FSW}$ of $\mathrm{Al}$ and $\mathrm{Mg}$ alloys, the heat-affected zone (HAZ) cannot be clearly observed within the FSW joints of 2205 DSS. And in advancing side (AS) of the weld, the border of the SZ and TMAZ is sharper than that in retreating side (RS), which is due to the more sufficient materials' flow within AS. And the high magnification optical micrographs of the TMAZ (Figure 6(c) and Figure 6(d)) show that the microstructure distribution within the weld cross section is asymmetrical: larger area of TMAZ is formed in RS of the joints, and the border of TMAZ and SZ is closer to the weld central line in RS.

The SEM images of BM etched with two kinds of solutions are shown in Figure 7. When using $\mathrm{KOH}$ solution (Figure $7(\mathrm{a})$ ), $\alpha$ is corroded preferentially; thus, the dark regions are $\alpha$. The volume fractions of $\alpha$ in BM are about $46 \%$. When using oxalic acid solution, the grain boundaries in both $\alpha$ and $\gamma$ are etched clearly, and $\alpha$ is corroded preferentially; thus, the lower and rougher grains within Figure 7(b) are $\alpha$. As shown in Figure 7, the elongated $\gamma$ islands are embedded in the $\alpha$ matrix along the rolling direction, and the $\gamma$ grains had a lower grain size than $\alpha$ grains. 


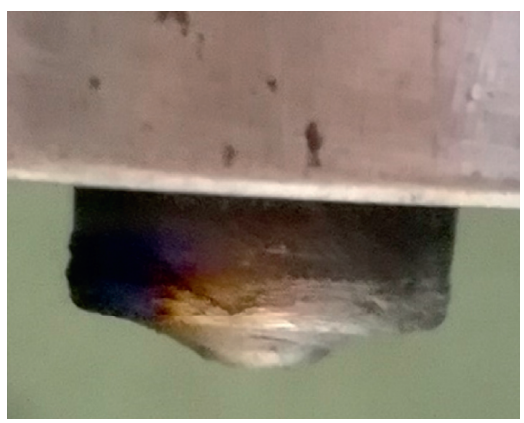

(a)

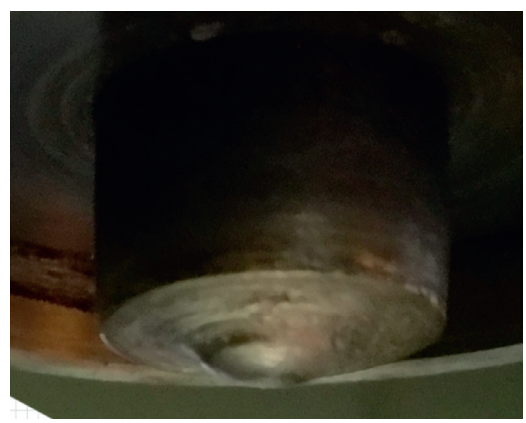

(b)

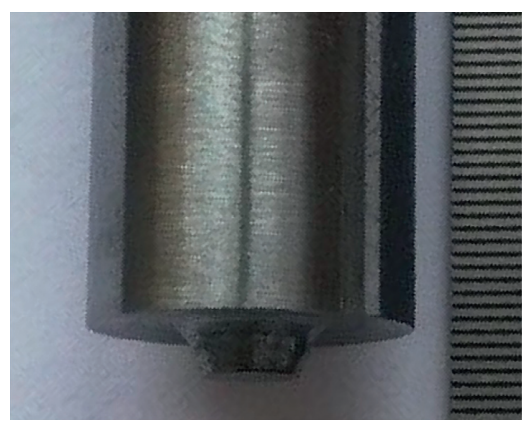

(c)

FIGURE 5: Serious sticking of tool: (a) after welding at $600 \mathrm{rpm}$, (b) after welding at $500 \mathrm{rpm}$, and (c) before welding.
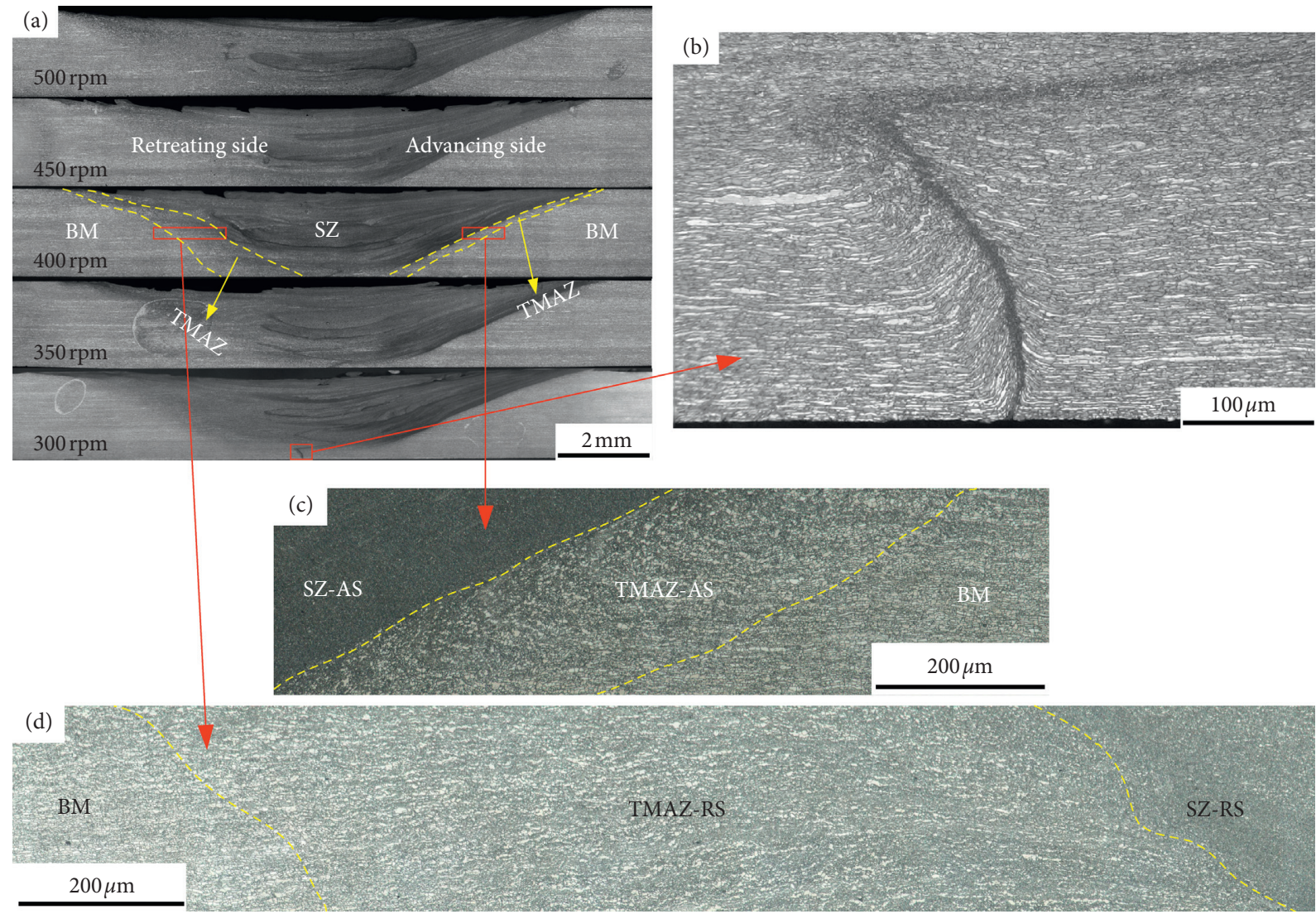

Figure 6: (a) The macrographs of the weld cross sections formed under different rotation speeds, (b) the lack of penetration defect in the joint welded at $300 \mathrm{rpm}$, (c) the micrograph of TMAZ-AS of the joint welded at $400 \mathrm{rpm}$, and (d) the micrograph of TMAZ-RS of the joint welded at $400 \mathrm{rpm}$.

To clearly interpret the microstructure in various zones of the joints, the TMAZ in AS and RS are named TMAZ-AS and TMAZ-RS, respectively; the SZ in AS, joint centre, and RS are named SZ-AS, SZ-CEN, and SZ-RS, respectively. As shown in Figure 8, a distorted structure is observed at the TMAZ, where it experienced the thermal and mechanical deformation during welding $[9,20]$. Near the border of TMAZ and SZ, the TMAZ-RS experienced a larger degree of deformation than TMAZ-AS; the distortion of the original rolling microstructure is more serious in TMAZ-RS. In SZ, the original rolling microstructure totally disappeared due to the full DRX. Regardless of the different temperature and deformation degree in TMAZ and SZ, under all conditions in present work, the phase ratio of $\alpha$ to $\gamma$ is almost constant. The volume fractions of ferrite in TMAZ and SZ of the joints welded at various rotation speeds are shown in Table 2. The $\alpha$ content, ranged between $44 \%$ and $52 \%$, has no systematic relationship with rotation speed or joint zones. Due to the solid-state nature of FSW, the heat input during FSW is significantly lower than that of fusion welding. In previous study on FSW of 2205 DSS, Santos et al. [11] showed that the peak temperature during FSW is lower than the phase 


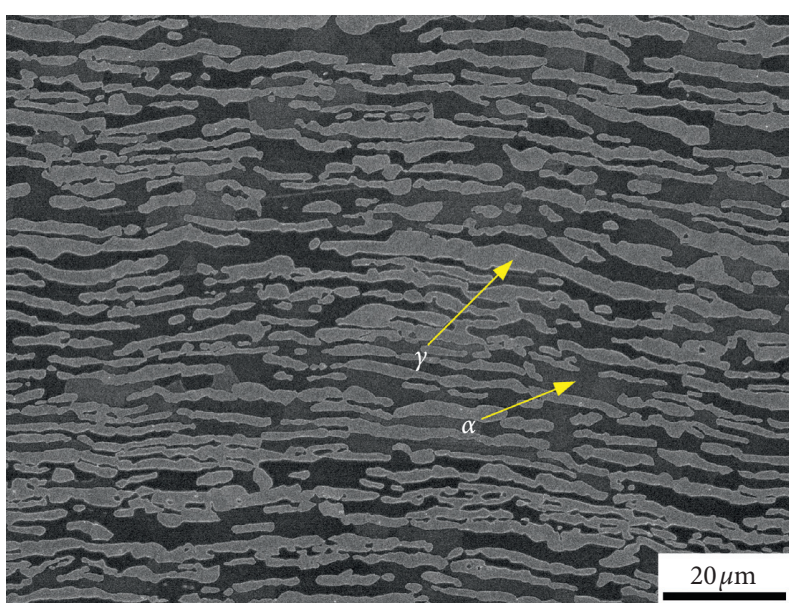

(a)

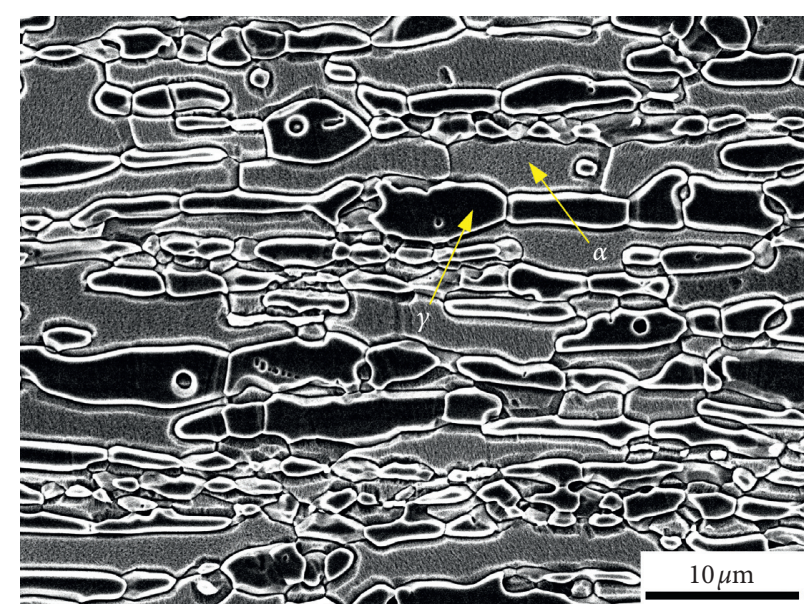

(b)

FIGURE 7: The SEM images of BM: (a) electroetched with KOH solution; (b) electroetched with oxalic acid solution.

transition temperature of $\gamma$ to $\alpha$. Under all welding parameters in this work, the 2205 DSS were welded in the twophase field of $\alpha+\gamma$, the ferritization process had not occur during the welding, and the small-range fluctuation of phase ratio might be due to the original fluctuation of the phase ratio in $\mathrm{BM}$.

The SEM images in TMAZ and SZ of the joints welded at different rotation speeds are shown in Figure 9, and the corresponding grain sizes of $\alpha$ and $\gamma$ are shown in Figure 10. The EDS results (Table 3 ) indicate that $\alpha$ contains more $\mathrm{Cr}$ and $\mathrm{Mo}$, and $\gamma$ contains more $\mathrm{Ni}$ and $\mathrm{Mn}$, which further confirms that the grains corroded preferentially during electrocorrosion are $\alpha$. In SZ (Figure 9), the original coarse and elongated $\alpha$ and $\gamma$ grains totally developed into the fine equiaxed grains due to full DRX. As for TMAZ, the grain sizes are also refined, especially the $\gamma$ grains. As shown in Figures $10(\mathrm{~d})$ and $10(\mathrm{f})$, the grain sizes of TMAZ-AS and TMAZ-RS were calculated in specific areas $(30 \mu \mathrm{m} \times 50 \mu \mathrm{m})$ near the border of TMAZ and SZ. In addition, at the same welding parameters, the grain size of TMAZ-RS is significantly finer than that of SZ, but a little bigger than that of TMAZ-AS.

Previous studies on FSW of DSS $[4,9,12,18]$ suggested that the fine equiaxial $\alpha$ and $\gamma$ grains within SZ are owing to the DRX. During FSW, SZ experienced elevated temperature and large degree plastic deformation, both $\alpha$ and $\gamma$ grains occur due to full DRX. Recent researches on FSW of DSS $[4,18]$ showed that continuous dynamic recrystallization (CDRX) occurs in both $\alpha$ and $\gamma$ within SZ, and static recrystallization (SRX) also occurs in $\gamma$ due to its lower stacking fault energy (SFE).

As shown in Figure 11, in the same joint, the grains in SZ-AS are finer than those in SZ-RS. The tool rotation orientations and the direction of welding speed are the same in AS; larger degree of deformation occurs in AS rather than RS. Accordingly, AS experienced higher temperature than RS. Previous study on FSW of DSS [11] shows that the peak temperature in TMAZ-AS is about $100 \mathrm{~K}$ higher than that in TMAZ-RS. Both strain rate and temperature have significant influence on recrystallization. Higher strain rate would lead to the smaller recrystallized grains, whereas the higher temperature would lead to the grain growth [4]. In SZ of the same joint, the strain rate seems to be the predominant factor, which resulted in the finest grains in AS and the coarsest grain in RS.

By contrast, under different rotation speed, the temperature became the predominant factor that determined the grain sizes of the SZ. As mentioned above, the higher rotation speed corresponds to the higher strain and also resulted in the higher peak temperature and longer cooling time. For a given material, the main factors that affected DRX are the strain rate and temperature; the higher strain rate would lead to finer recrystallized grains, whereas the higher peak temperature might lead to significant grain coarseness [29-31]. What is more, the longer cooling time after dynamical recrystallization might also coarsen the recrystallized grain. As shown in Figures 9 and 10, the grain size of SZ increases with the increasing of rotation speed, which indicates that, under different rotation speeds, the predominant factor that determined the grain size of SZ is temperature rather than strain rate. As shown in Figures 9, 10 , and 11, in SZ, the $\alpha$ grains are coarser than the $\gamma$ grains. This is because of the different crystal structures between $\alpha$ and $\gamma . \alpha$ has more slip systems and higher SFE than $\gamma$ which facilitates the dislocation activities and accelerates DRX in $\alpha$. Thus, the dynamic recrystallized $\alpha$ grains in SZ also experienced more serious grain growth than $\gamma$ grains during the cooling phase [4].

As for TMAZ, regardless of AS or RS, near the border of TMAZ/SZ, the grains tend to distortion along the direction of applied stress (Figures 6, 8, and 9). In addition, both the $\alpha$ and $\gamma$ grains were significantly refined, especially the $\gamma$ grains (Figure 10). In fact, the TMAZ experienced lower degree of plastic deformation and lower temperature than SZ which is insufficient for full DRX $[4,20]$, whereas partial recrystallization must occur near the border of TMAZ/SZ, especially in $\gamma$ grains [32]. The mechanisms of grain refining are different for $\alpha$ and $\gamma$ due to their different crystal structure 


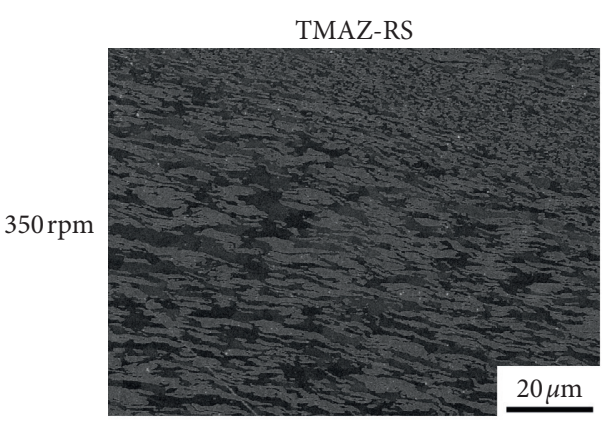

(a)

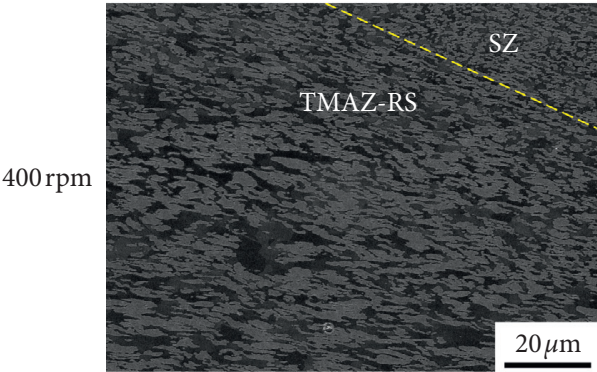

(d)

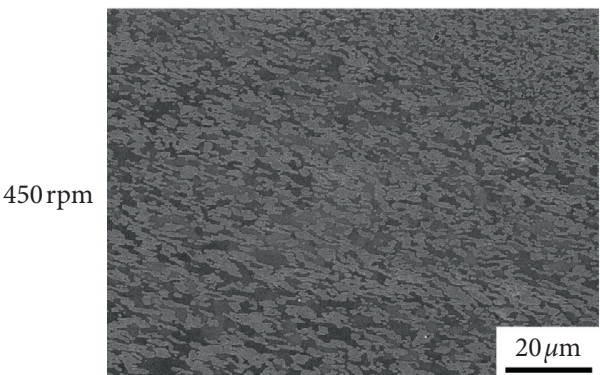

(g)

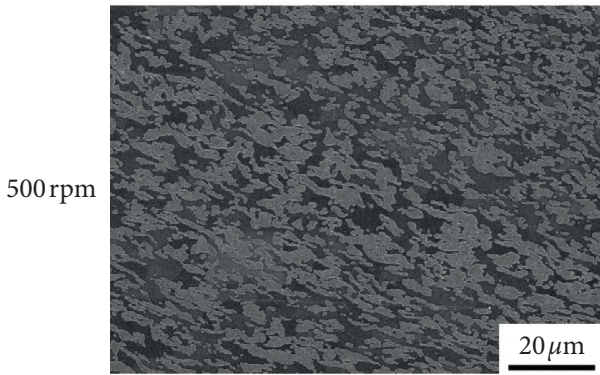

(j)

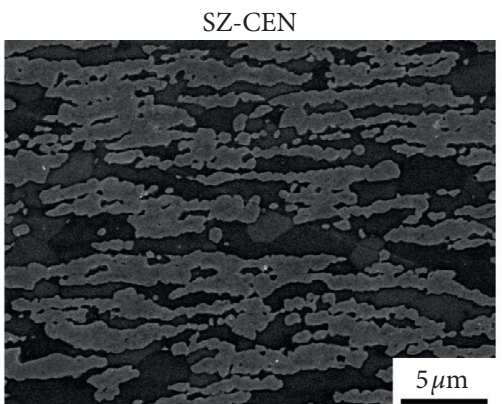

(b)

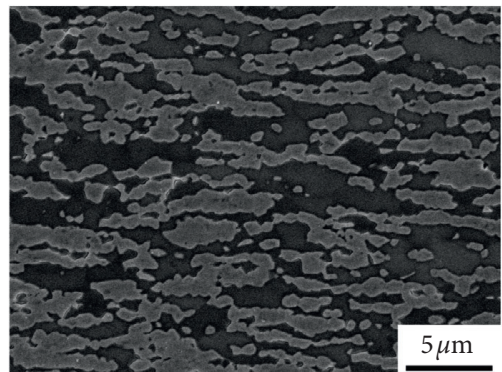

(e)

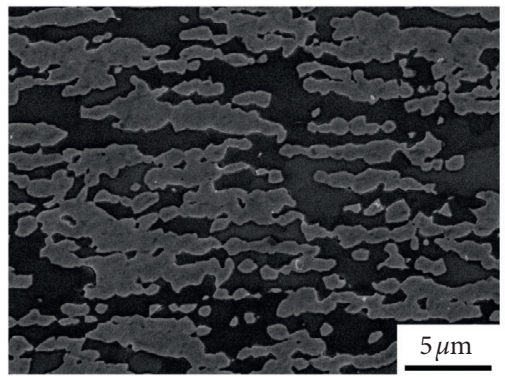

(h)

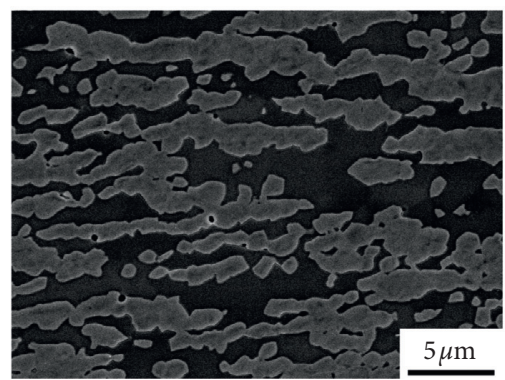

(k)
TMAZ-AS

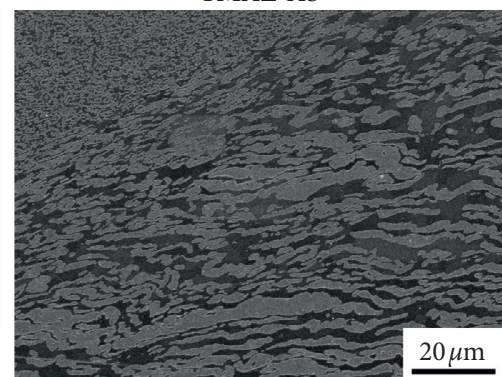

(c)

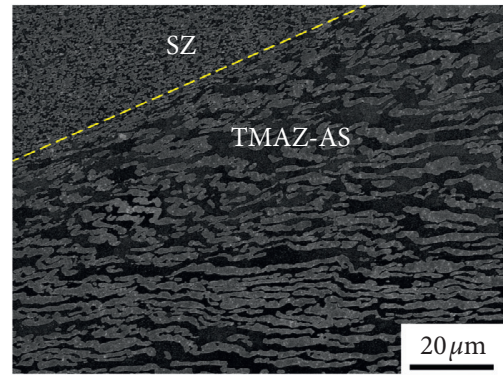

(f)

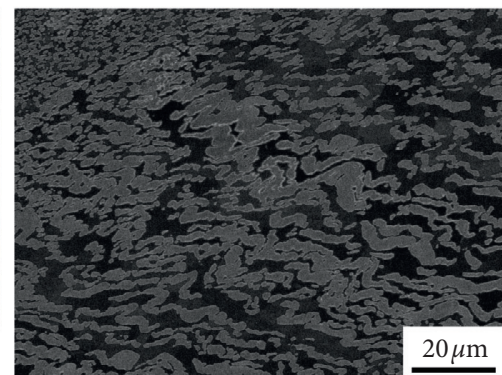

(i)

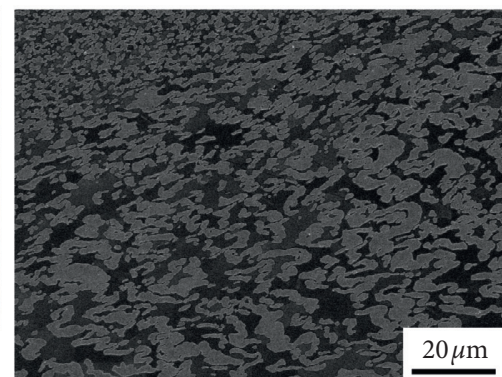

(l)

FIGURE 8: The SEM images in TMAZ and SZ of the joints welded at various rotation speeds (electroetched with KOH solution).

TABLE 2: Volume fraction of ferrite in TMAZ and SZ of the joints welded at various rotation speeds.

\begin{tabular}{lccc}
\hline \multirow{2}{*}{ Rotation speed $(\mathrm{rpm})$} & \multicolumn{2}{c}{ Volume fraction of ferrite (\%) } \\
& TMAZ-RS & SZ-CEN & TMAZ-AS \\
\hline 500 & 46.0 & 48.1 & 45.4 \\
450 & 51.0 & 49.4 & 47.2 \\
400 & 45.1 & 51.2 & 47.8 \\
350 & 47.6 & 44.9 & 44.7 \\
\hline
\end{tabular}

[32, 33]. $\alpha$, with body-centered cubic (BCC) crystal structure, has high SFE and many slip systems. $\alpha$ is the softer phase and can accommodate larger strains than $\gamma$. The climb and cross-slip of dislocations are easier occur in $\alpha$ during high-temperature deformation, and the deformed structure favours dynamic recovery (DRV) rather than DRX. On the 


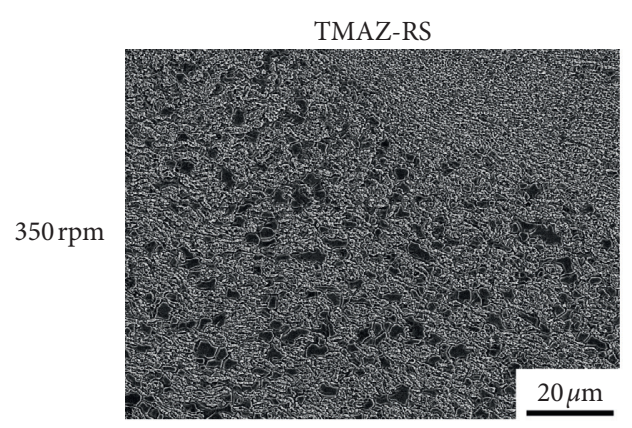

(a)

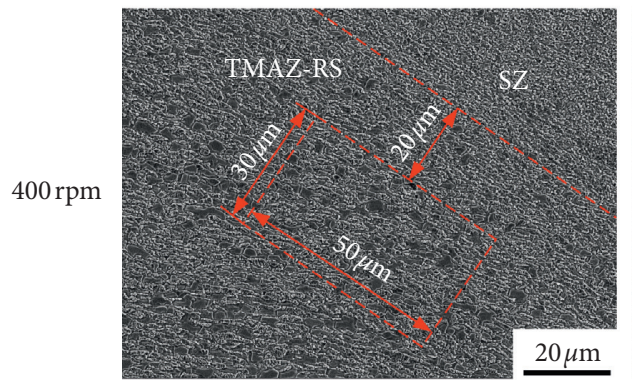

(d)

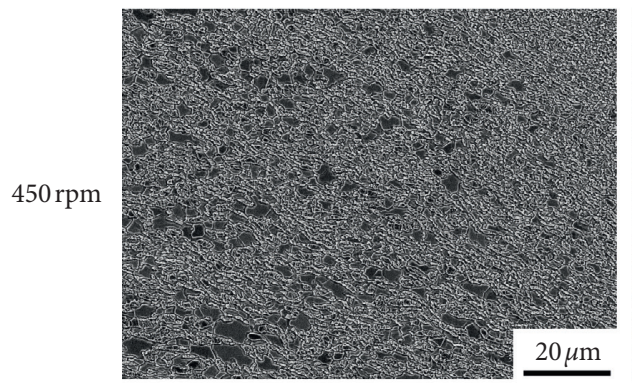

(g)

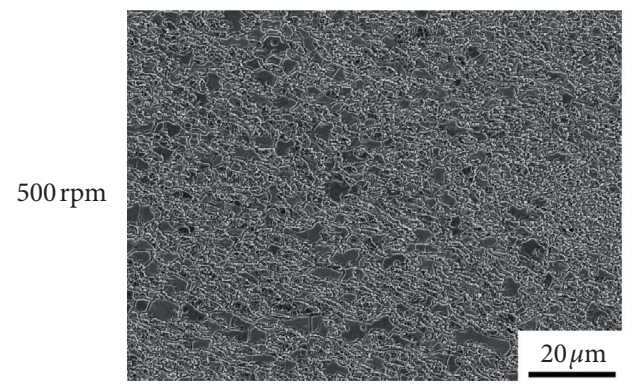

(j)

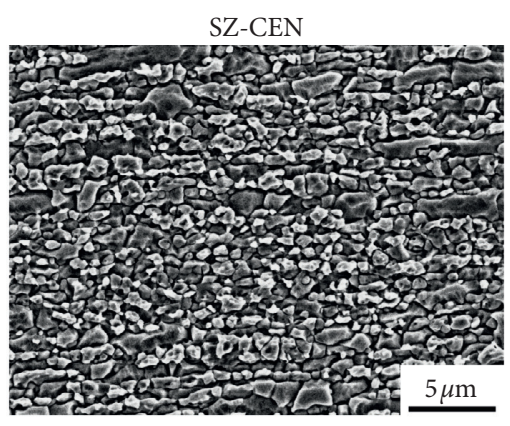

(b)

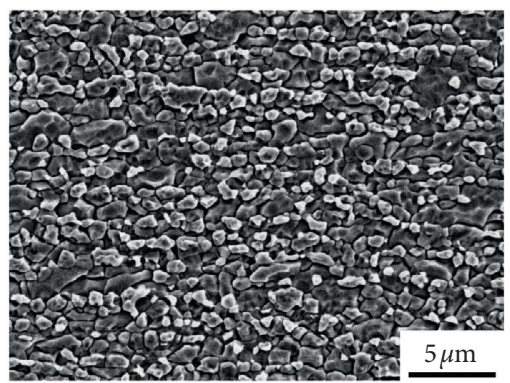

(e)

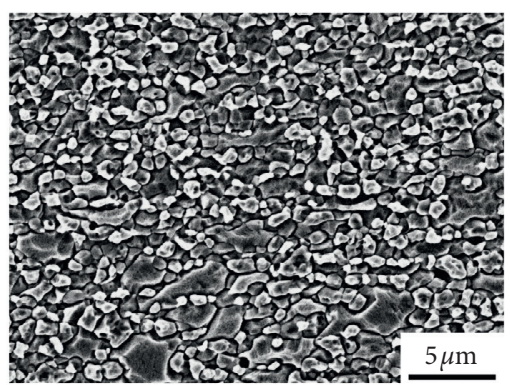

(h)

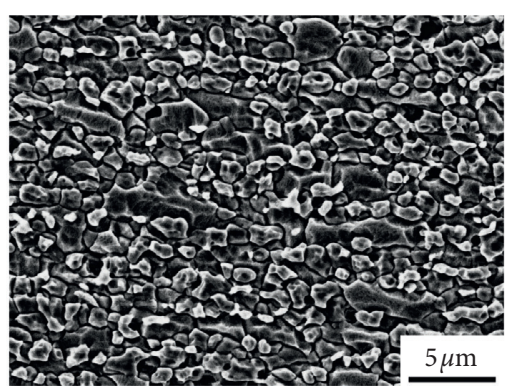

(k)

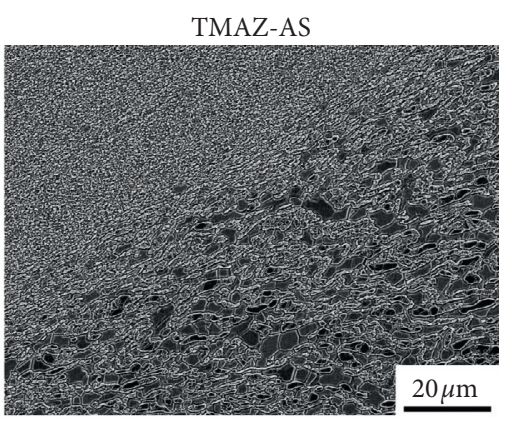

(c)

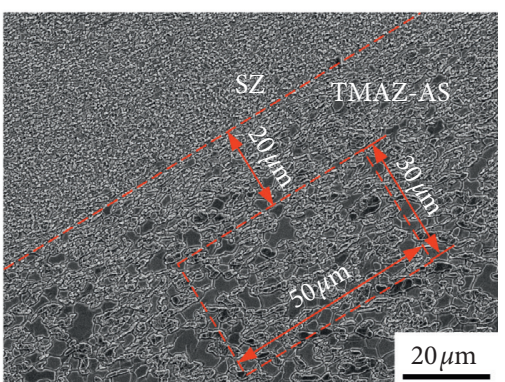

(f)

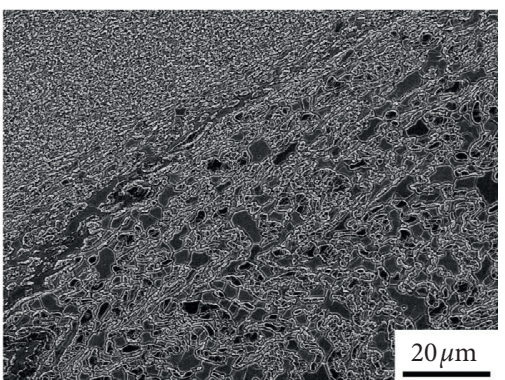

(i)

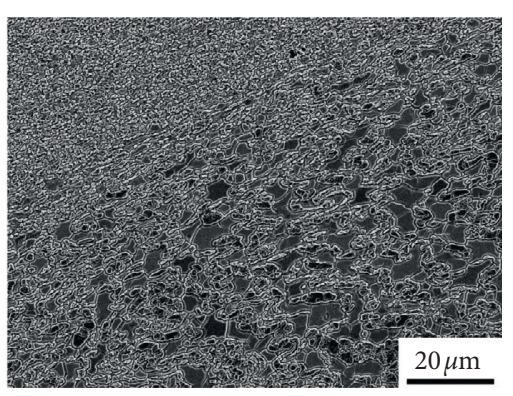

(1)

FIGURE 9: SEM images in TMAZ and SZ of the joints welded at various rotation speeds (electroetched with oxalic acid solution).

contrary, $\gamma$, with face-centered cubic (FCC) crystal structure, has lower SFE and fewer slip systems, favouring DRX rather than DRV in high temperature deformation. Due to the different grain refining mechanisms between the constituent phases in DSS, $\gamma$ grains are significantly finer than $\alpha$ grains in TMAZ (Figure 10). The sizes of $\gamma$ grains in TNAZ-RS are comparable to those in SZ-CEN, which indicates that DRX is the main grain refining mechanism of $\gamma$ in TMAZ near the border of TMAZ/SZ. In addition, the initial size difference between $\alpha$ and $\gamma$ grains in BM (Figures 7 and 10) also has influence on the grain size difference between $\alpha$ and $\gamma$ grains in TMAZ.
Different from the SZ, near the border of the TMAZ/SZ in the same joints, the grains in TMAZ-RS are finer than those in TMAZ-AS (Figures 9 and 10). As mentioned above, AS has higher temperature than RS; the peak temperature in TMAZ-AS is lower than that in TMAZ-RS [11]. The occurrence of DRX in SZ needs sufficient temperature and strain; at lower deformation temperature, larger strain is needed to initiate the DRX. Thus, the border of TMAZ/SZ is closer to the joint centre (Figure 6). Near the border of TMAZ/SZ, the lower temperature and larger strain in TMAZ-RS resulted in the finer grains in TMAZ-RS. In addition, the closer distance between the border of 


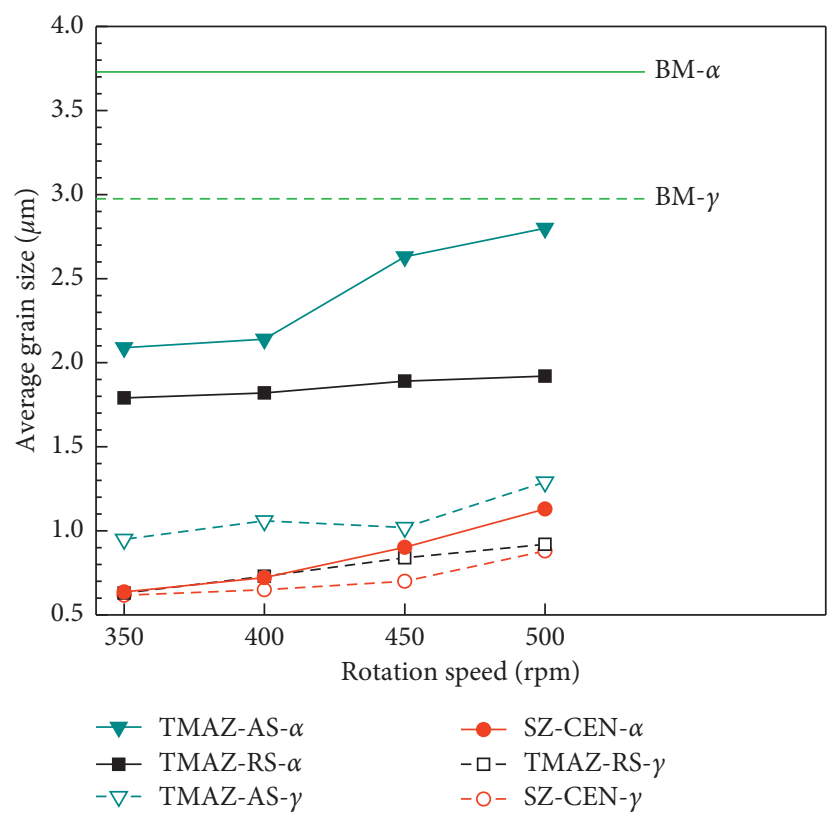

FIGURE 10: Grain sizes of $\alpha$ and $\gamma$ in TMAZ and SZ of the joints welded at different rotation speeds.

TABLE 3: Chemical compositions of the recrystallized ferrite and austenite in SZ (wt\%).

\begin{tabular}{lcccc}
\hline Phases & $\mathrm{Cr}$ & $\mathrm{Mo}$ & $\mathrm{Ni}$ & \\
\hline (Ferrite) $\alpha$ & 23.57 & 3.13 & 5.18 & $\mathrm{Mn}$ \\
(Austenite) $\gamma$ & 20.38 & 2.81 & 5.99 & 0.85 \\
\hline
\end{tabular}

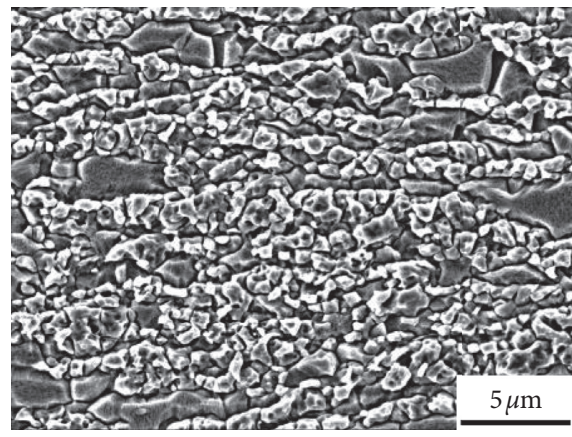

SZ-RS: $\mathrm{D} \alpha=0.79 \mu \mathrm{m}, \mathrm{D} \gamma=0.64 \mu \mathrm{m}$

(a)

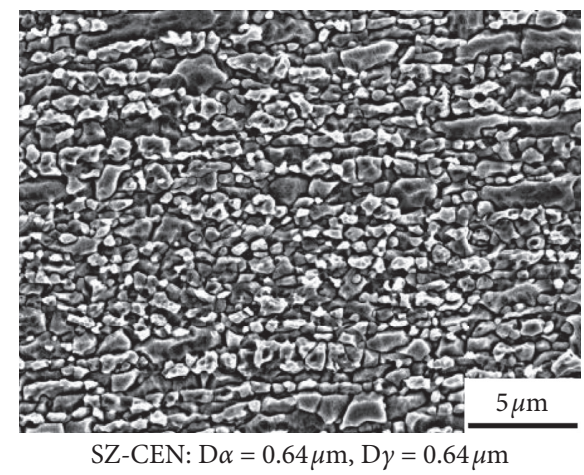

(b)

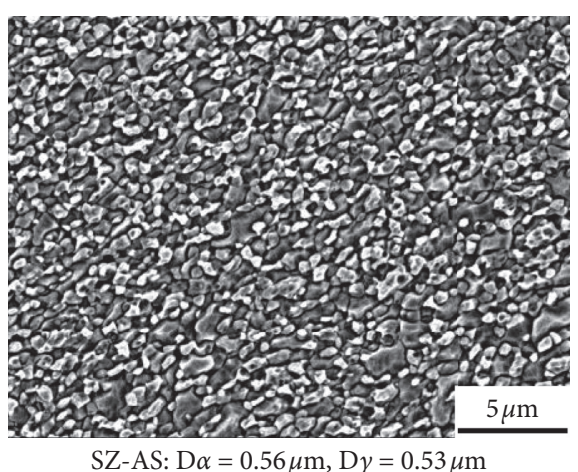

(c)

FIGURE 11: The SEM images and corresponding grain sizes in SZ of the joint welded at $350 \mathrm{rpm}$ (electroetched with oxalic acid solution): (a) in the retreating side, (b) in the centre, and (c) in the advancing side. 


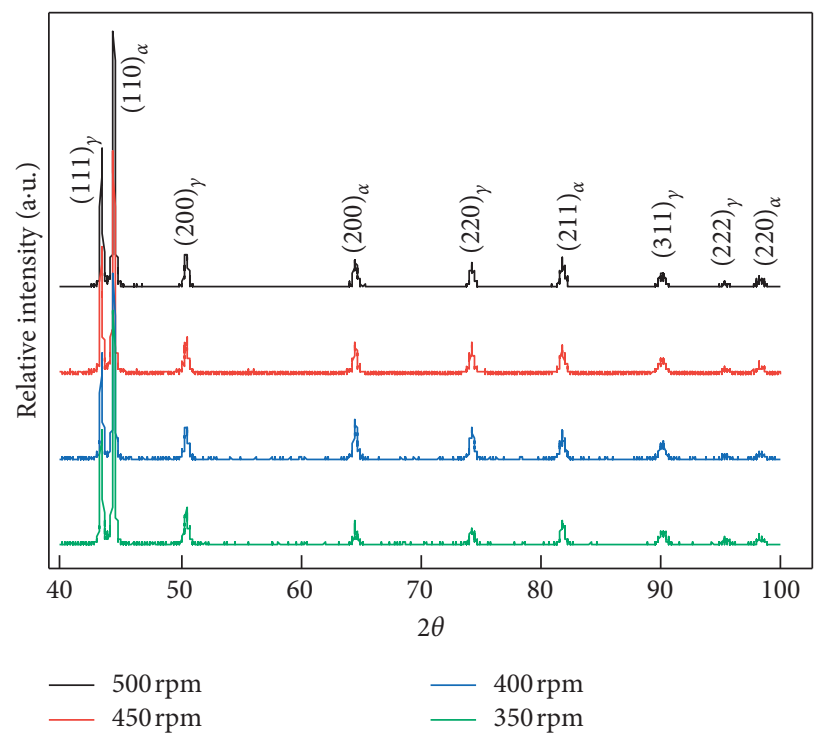

FIgURE 12: X-ray diffraction patterns for the welds formed at various rotation speeds.
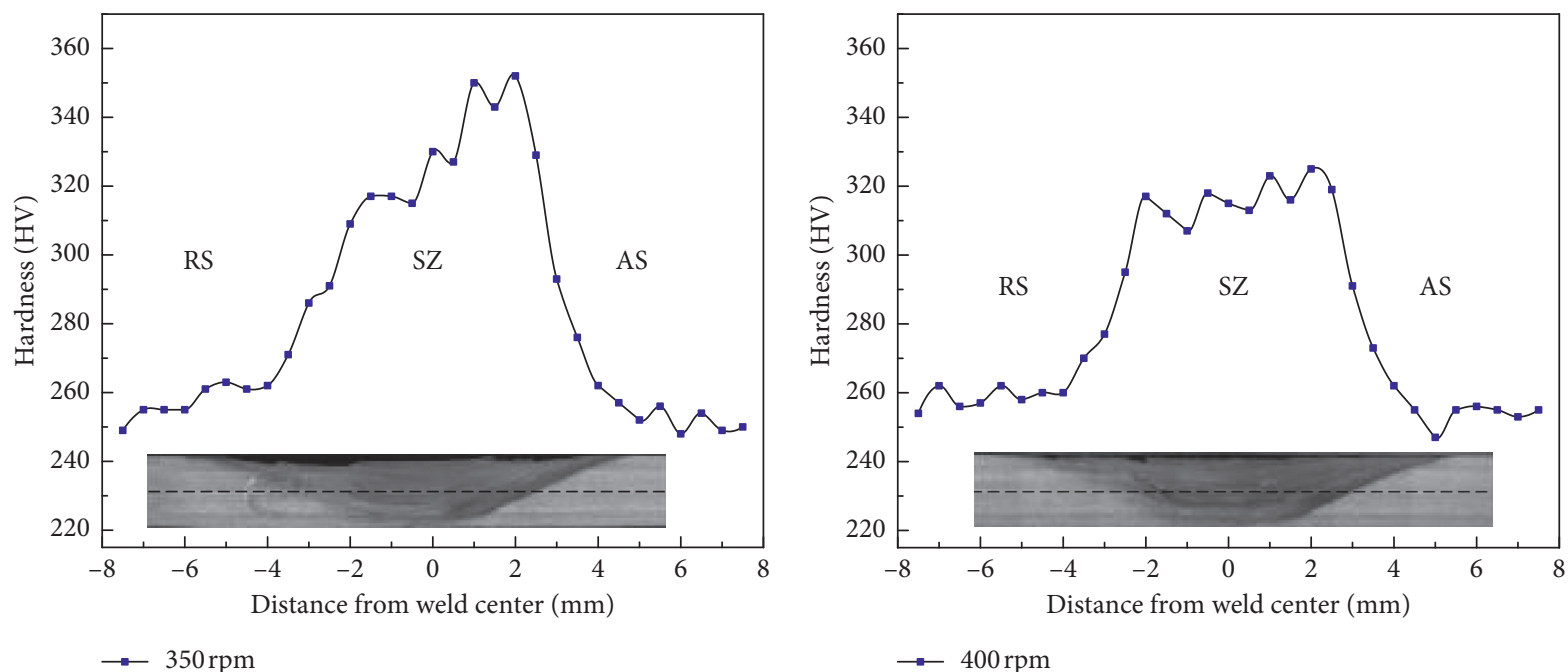

(a)

(b)
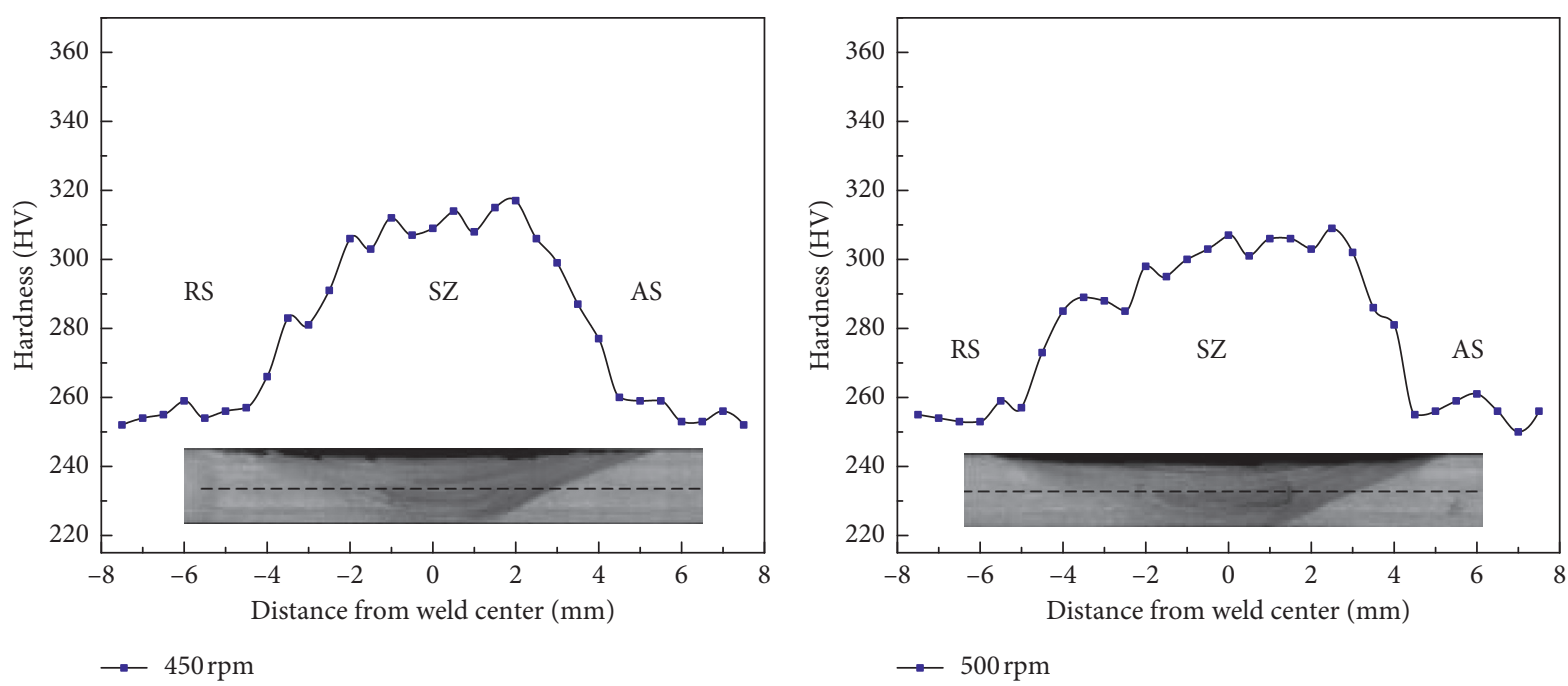

(c)

(d)

FIGURE 13: Typical hardness profile of the joints welded at different rotation speeds. 


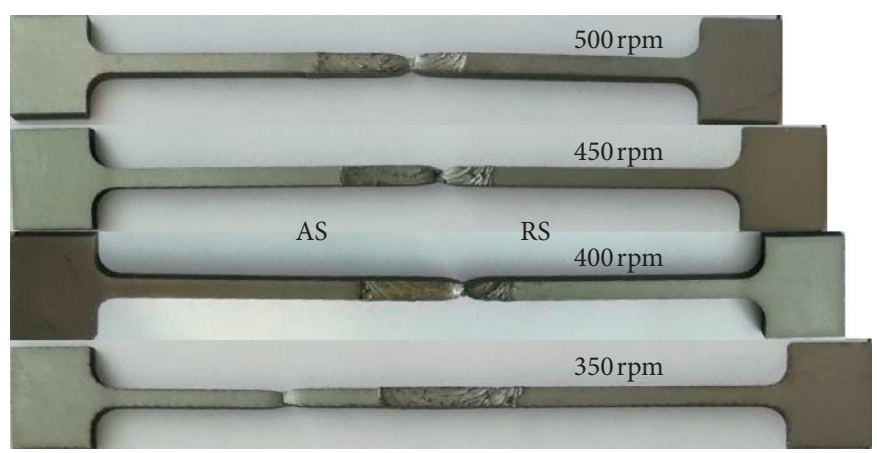

(a)

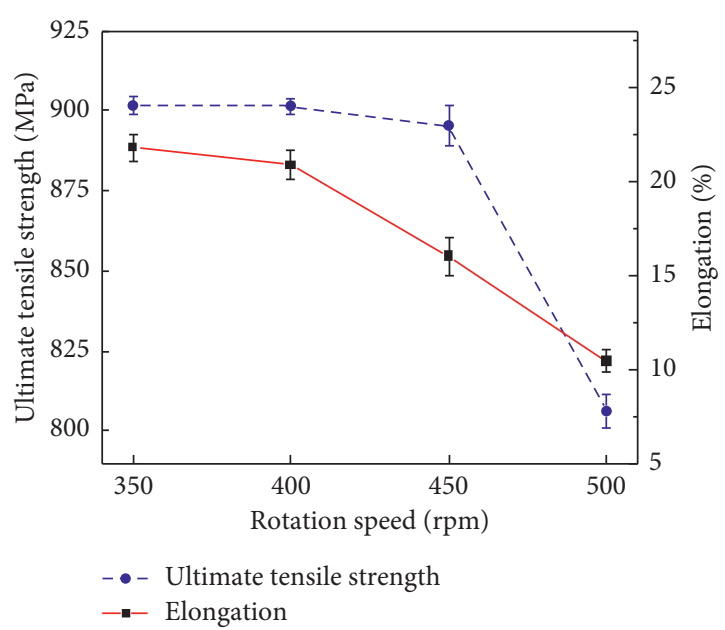

(b)

Figure 14: (a) The macrographs of the tensile samples after fracture. (b) Recorded tensile strength and the percentage elongation after fracture of the tensile samples change with rotation speed.

TMAZ/SZ and weld centerline also resulted in a larger area of TMAZ in AS.

As mentioned above, the higher rotation speed corresponds to the higher strain and also resulted in the higher peak temperature and longer cooling time. In TMAZ, after grain refining by DRX or DRV, the higher peak temperature and longer cooling time would result in more serious grain growing in both $\alpha$ and $\gamma$. Therefore, the grain size in TMAZ also increases with the increasing rotation speed.

Figure 12 shows the XRD patterns of the joints welded at various rotation speeds. The diffraction peaks are matched with $\alpha$ and $\gamma$ phases. It should be noted that no detrimental intermetallic phases were observed both in the XRD patterns (Figure 12) and the SEM images (Figures 8 and 9). Sigma $(\sigma)$ phase, the most detrimental intermetallic phase, usually forms at a long time of heat preservation at $650^{\circ} \mathrm{C}$ to $950^{\circ} \mathrm{C}$ in fusion welding $[2,3]$. Previous researches on 2205 DSS $[3,34,35]$ showed that the formation of $s$ phase can be prevented when the cooling rate is greater than $0.25 \mathrm{~K} \cdot \mathrm{s}^{-1}$. From Figure 3(a), we can know that the cooling rate of the welds is far higher than $0.25 \mathrm{~K} \cdot \mathrm{s}^{-1}$; thus, $\sigma$ phase did not form in the welds.

3.4. Mechanical Properties. Typical hardness profiles of the joints welded at different rotation speeds are shown in Figure 13. SZ exhibits the highest hardness of the weld, and TMAZ also shows higher hardness than BM. SZ-AS exhibits higher hardness than SZ-RS. And the hardness of both SZ and TMAZ decreases with the increasing rotation speeds. These hardness profiles for the joints welded at different rotation speeds can be interpreted by the Hall-Petch relationship well. The Hall-Petch relationship on steels indicates that the mechanical resistance is negatively related to the grain size $[36,37]$. The finer grains correspond to higher hardness and strength. The hardness profiles (Figure 13) corresponded well with the grain size distribution (Figure 10). In addition, it can be deduced from the hardness profiles (Figure 13) that the joint width increases with the increasing of rotation speed. As mentioned above, the higher rotation speed would lead to a larger heat input during welding. Therefore, the joint width also increases with the increasing of rotation speed.

The tensile test results for the joints are shown in Figure 10. We can see that the tensile specimens of $400 \mathrm{rpm}, 450 \mathrm{rpm}$, and $500 \mathrm{rpm}$ failed near the border of SZ/TMAZ-RS within the joints, and the specimens of $350 \mathrm{rpm}$ failed within BM.

It should be pointed out that the thickness within the SZ was reduced to about $1.55 \mathrm{~mm}$ by FSW due to the tool tilting during FSW, and the thickness gradually increases from the weld centerline to the BM $(1.86 \mathrm{~mm})$. The gauge section of the tensile samples not only includes the 12mm-wide joints, but also contains BM section $(1.86 \mathrm{~mm}$ thick). Therefore, the actual tensile stress within the joints was higher than that within BM during the tensile testing. Although the joints have finer grains and higher hardness than $\mathrm{BM}$, the tensile sample is still fractured within the joints welded at $400-500 \mathrm{rpm}$. This phenomenon is well consistent with the study of Sato et al. [14] on the FSW of 2507 DSS. As mentioned above, TMAZ has coarser grains and lower hardness than SZ. TMAZ is the comparably weak regions in the joints. In addition, the shape of joint zone (SZ and TMAZ) is like a basin (Figure 6(a)). Although TMAZ-RS has higher hardness and finer grains than TMAZ-AS, TMAZ-RS is closer to the joint centerline (Figure 6). Near the border of TMAZ/SZ, TMAZ-RS exhibits a smaller sickness than TMAZ-AS. And TMAZ-RS is significantly wider than TMAZ-AS as well. Thus, the weakest region within tensile samples for the joints welded at $400-500 \mathrm{rpm}$ is near the border of SZ/TMAZ-RS, and the samples are fractured therein.

As for the tensile sample for the joint welded at $350 \mathrm{rpm}$, it is fractured in BM. This is because that the joint welded at $350 \mathrm{rpm}$ has the finest grains, highest hardness, and smallest welding-affected zone. Therefore, it exhibits the best tensile properties, fractured in BM. 
From the image of fractured tensile samples (Figure 14(a)), we can see that the necking phenomenon is apparent at all fractured samples, which indicates that the FSW joints had good ductility. The fractured sample for the joint welded at $350 \mathrm{rpm}$ exhibits a large degree of plastic deformation which indicates that it also has good ductility. From the tensile test results for the joints welded at different rotation speeds (Figure 14(b)), we can conclude that the ultimate tensile strength (UTS) of the joint welded at $400 \mathrm{rpm}$ is comparable to $\mathrm{BM}$, and UTS of the joint welded at $450 \mathrm{rpm}$ is about $99 \%$ of $\mathrm{BM}$, and UTS of the joint welded at $500 \mathrm{rpm}$ is about $90 \%$ of BM. In addition, both the ultimate tensile strength (UTS) and the elongation after fracture of the joints are decreased with the increasing rotation speeds, which matched well with corresponding hardness profiles (Figure 13).

\section{Conclusion}

This paper mainly studied the effect of rotation speed on the microstructure and mechanical properties of friction-stirwelded 2205 DSS.

Sound welds were formed at rotation speeds of 350 to $500 \mathrm{rpm}$, whereas the lack of penetration defect was formed at lower rotation speed of $300 \mathrm{rpm}$ because of the insufficient heat input. The sticking of tool is closely related to the rotation speed; the high rotation speed would result in serious sticking on tungsten-rhenium-based tool during FSW of 2205 DSS. Macroscopic groove-like defect was formed at $600 \mathrm{rpm}$ because of the serious sticking of tool.

The grain sizes of SZ and TMAZ are negatively correlated with rotation speed, and the hardness of SZ and TMAZ also increases with the increasing of the rotation speed. In addition, the joint width increases with the increasing of rotation speed. Therefore, the joints with higher strength are formed at lower rotation speed. And these phenomena can be interpreted by the fact that the higher rotation speed would result in the larger heat input and higher peak temperatures during FSW. The FSW process does not change the phase ratio of $\alpha$ to $\gamma$ within TMAZ and SZ. The predominant strengthening mechanism for the joints is grain refining.

\section{Data Availability}

Some of the data required to reproduce these findings cannot be shared at this time as the data also form part of an ongoing study.

\section{Conflicts of Interest}

The authors declare that there are no conflicts of interest regarding the publication of this paper.

\section{Acknowledgments}

This research was funded by the Program for JLU Science and Technology Innovative Research Team (2017TD-04), the Jilin Provincial Middle and Young Scientific and Technological Innovation Talent and Team Project (20170519001JH), the National Key R and D Program of
China (2018YFF01012400), and the "Double Ten Project" of Scientific and Technological Innovation of Changchun (18SS009).

\section{References}

[1] T. F. D. A. Santos, E. A. Torres, and A. J. Ramirez, "Soldagem por atrito com pino não consumível de aços inoxidáveis duplex," Soldagem \& Inspeção, vol. 21, no. 1, pp. 59-69, 2016.

[2] A. R. Ingraffea and P. A. Wawrzynek, Encyclopedia of Materials: Science and Technology, Elsevier, New York, NY, USA, 2001.

[3] J. C. Lippold and D. J. Kotecki, Welding Metallurgy and Weldability of Stainless Steel, John Wiley \& Sons, Hoboken, NJ. USA, 2005.

[4] S. Emami, T. Saeid, and R. A. Khosroshahi, "Microstructural evolution of friction stir welded SAF 2205 duplex stainless steel," Journal of Alloys and Compounds, vol. 739, pp. 678689, 2018.

[5] A. Pramanik, G. Littlefair, and A. K. Basak, "Weldability of duplex stainless steel," Materials and Manufacturing Processes, vol. 30, no. 9, pp. 1053-1068, 2015.

[6] P. D. Babu, P. Gouthaman, and P. Marimuthu, "Effect of heat sink and cooling mediums on ferrite austenite ratio and distortion in laser welding of duplex stainless steel 2205," Chinese Journal of Mechanical Engineering, vol. 32, no. 1, p. 9, 2019.

[7] B. Varbai, Y. Adonyi, R. Baumer et al., "Weldability of Duplex Stainless Steels - thermal Cycle and Nitrogen Effects Duplex stainless steel weld microstructures were investigated as a function of weld thermal cycles and shielding gas nitrogen content," Welding Journal, vol. 98, no. 3, pp. 78S-87S, 2019.

[8] S. H. Arabi, M. Pouranvari, and M. Movahedi, "Pathways to improve the austenite-ferrite phase balance during resistance spot welding of duplex stainless steels," Science and Technology of Welding and Joining, vol. 24, no. 1, pp. 8-15, 2019.

[9] M. Esmailzadeh, M. Shamanian, A. Kermanpur, and T. Saeid, "Microstructure and mechanical properties of friction stir welded lean duplex stainless steel," Materials Science and Engineering: A, vol. 561, pp. 486-491, 2013.

[10] A. M. d. S. Leite, M. Terada, V. F. Pereira, E. B. d. Fonseca, N. B. d. Lima, and I. Costa, "On the pitting resistance of friction stir welded UNS S82441 lean duplex stainless steel," Journal of Materials Research and Technology, vol. 8, no. 3, pp. 3223-3233, 2019.

[11] T. F. A. Santos, H. S. Idagawa, and A. J. Ramirez, "Thermal history in UNS S32205 duplex stainless steel friction stir welds," Science and Technology of Welding and Joining, vol. 19, no. 2, pp. 150-156, 2014.

[12] T. Saeid, A. Abdollah-zadeh, H. Assadi et al., "Effect of friction stir welding speed on the microstructure and mechanical properties of a duplex stainless steel," Materials Science and Engineering: A, vol. 496, no. 1-2, pp. 262-268, 2008.

[13] M. Magnani, M. Terada, A. O. Lino et al., "Microstructural and electrochemical characterization of friction stir welded duplex stainless steels," International Journal of Electrochemical Science, vol. 9, no. 6, pp. 2966-2977, 2014.

[14] Y. S. Sato, T. W. Nelson, C. J. Sterling et al., "Microstructure and mechanical properties of friction stir welded SAF 2507 super duplex stainless steel," Materials Science and Engineering: A, vol. 397, no. 1-2, pp. 376-384, 2005.

[15] R. A. R. Giorjão, V. F. Pereira, M. Terada et al., "Microstructure and mechanical properties of friction stir welded $8 \mathrm{~mm}$ pipe SAF 2507 super duplex stainless steel," Journal of 
Materials Research and Technology, vol. 8, no. 1, pp. 243-249, 2019.

[16] W. L. Chen, J. Wang, J. C. Li et al., "Effect of the rotation speed during friction stir welding on the microstructure and corrosion resistance of SAF 2707 hyper duplex stainless steel," Steel research international, vol. 89, no. 4, 2018.

[17] J. Li, X. Liu, G. Li, P. Han, and W. Liang, "Characterization of the microstructure, mechanical properties, and corrosion resistance of a friction-stir-welded joint of hyper duplex stainless steel," Metals, vol. 7, no. 4, p. 138, 2017.

[18] T. Saeid, A. Abdollah-zadeh, T. Shibayanagi et al., "On the formation of grain structure during friction stir welding of duplex stainless steel," Materials Science and Engineering: $A$, vol. 527, no. 24-25, pp. 6484-6488, 2010.

[19] T. F. A. Santos, R. R. Marinho, M. T. P. Paes, and A. J. Ramirez, "Microstructure evaluation of UNS S32205 duplex stainless steel friction stir welds," Rem: Revista Escola de Minas, vol. 66, no. 2, pp. 187-191, 2013.

[20] R. S. Mishra and Z. Y. Ma, "Friction stir welding and processing," Materials Science and Engineering: R: Reports, vol. 50, no. 1-2, pp. 1-78, 2005.

[21] H. J. Zhang, M. Wang, Z. Zhu, X. Zhang, T. Yu, and Z. Q. Wu, "Nugget structure evolution with rotation speed for highrotation-speed friction-stir-welded 6061 aluminum alloy," Journal of Materials Engineering and Performance, vol. 27, no. 3, pp. 1378-1386, 2018.

[22] K. Yabuuchi, N. Tsuda, A. Kimura et al., "Effects of tool rotation speed on the mechanical properties and microstructure of friction stir welded ODS steel," Materials Science and Engineering: A, vol. 595, pp. 291-296, 2014.

[23] G. d. Q. Caetano, C. C. Silva, M. F. Motta et al., "Influence of rotation speed and axial force on the friction stir welding of AISI 410 S ferritic stainless steel," Journal of Materials Processing Technology, vol. 262, pp. 430-436, 2018.

[24] X. Liu, S. Lan, and J. Ni, "Electrically assisted friction stir welding for joining $\mathrm{Al} 6061$ to TRIP 780 steel," Journal of Materials Processing Technology, vol. 219, pp. 112-123, 2015.

[25] $\varnothing$. Frigaard, Ø. Grong, and O. T. Midling, "A process model for friction stir welding of age hardening aluminum alloys," Metallurgical and Materials Transactions A, vol. 32, no. 5, pp. 1189-1200, 2001.

[26] H.-B. Chen, K. Yan, T. Lin, S.-B. Chen, C.-Y. Jiang, and Y. Zhao, "The investigation of typical welding defects for 5456 aluminum alloy friction stir welds," Materials Science and Engineering: A, vol. 433, no. 1-2, pp. 64-69, 2006.

[27] S. Cui, Z. W. Chen, and J. D. Robson, "A model relating tool torque and its associated power and specific energy to rotation and forward speeds during friction stir welding/processing," International Journal of Machine Tools and Manufacture, vol. 50, no. 12, pp. 1023-1030, 2010.

[28] Y. G. Kim, H. Fujii, T. Tsumura, T. Komazaki, and K. Nakata, "Three defect types in friction stir welding of aluminum die casting alloy," Materials Science and Engineering: A, vol. 415, no. 1-2, pp. 250-254, 2006.

[29] F. J. Humphreys and M. Hatherly, Recrystallization and Related Annealing Phenomena, Elsevier, Amsterdam, Boston, 2nd edition, 2004.

[30] K. V. Jata and S. L. Semiatin, "Continuous dynamic recrystallization during friction stir welding of high strength aluminum alloys," Scripta Materialia, vol. 43, no. 8, pp. 743-749, 2000.

[31] H. J. McQueen and N. D. Ryan, "Constitutive analysis in hot working," Materials Science and Engineering: A, vol. 322, no. 1-2, pp. 43-63, 2002.
[32] T. F. A. Santos, E. A. Torres, J. C. Lippold, and A. J. Ramirez, "Detailed microstructural characterization and restoration mechanisms of duplex and superduplex stainless steel friction-stir-welded joints," Journal of Materials Engineering and Performance, vol. 25, no. 12, pp. 5173-5188, 2016.

[33] L. Duprez, B. C. De Cooman, and N. Akdut, "Flow stress and ductility of duplex stainless steel during high-temperature torsion deformation," Metallurgical and Materials Transactions A, vol. 33, no. 7, pp. 1931-1938, 2002.

[34] T. H. Chen and J. R. Yang, "Effects of solution treatment and continuous cooling on $\sigma$-phase precipitation in a 2205 duplex stainless steel," Materials Science and Engineering: A, vol. 311, no. 1-2, pp. 28-41, 2001.

[35] H. Sieurin and R. Sandström, "Austenite reformation in the heat-affected zone of duplex stainless steel 2205," Materials Science and Engineering: A, vol. 418, no. 1-2, pp. 250-256, 2006.

[36] K. Takeda, N. Nakada, T. Tsuchiyama, and S. Takaki, "Effect of interstitial elements on Hall-Petch coefficient of ferritic iron," ISIJ International, vol. 48, no. 8, pp. 1122-1125, 2008.

[37] S. Rajasekhara, P. J. Ferreira, L. P. Karjalainen, and A. Kyröläinen, "Hall-Petch behavior in ultra-fine-grained AISI 301LN stainless steel," Metallurgical and Materials Transactions A, vol. 38, no. 6, pp. 1202-1210, 2007. 